\title{
Modified Starch-Enhanced Ultrafiltration for Chromium (VI) Removal
}

\author{
Patcharin Racho and Pinitta Phalathip
}

\begin{abstract}
With increasing concerns about environmental protection are being made to develop biodegradable starch-based materials using in pollutant treatment, particularly for heavy metals removal. This study was investigated on two cross-linkages of modified starch including amino and carboxyl as the sorbents to remove hexavalent chromium from aqueous solution. The overall resulted showed that only amino crosslinking starch was effective on $\mathrm{Cr}$ (VI) chemisorption. The carboxyl crosslinking and non-modified starch were showed too poor adsorption performances. The $\mathrm{pH}$ of the aqueous solutions is an important controlling parameter in the heavy metal adsorption processes. The highest efficiency was achieved in acidic condition about pH 5. However, modified starch is an organic material so it can be contaminated in the effluent. The ultrafiltration was used to separate modified starch from the effluent for sufficiently treatment. Also the operating conditions of modified starch enhanced ultrafiltration for chromium (VI) removal were evaluated in this study.
\end{abstract}

Index Terms-Modified starch, chemisorptions, heavy metal removal.

\section{INTRODUCTION}

Soluble hexavalent chromium (Cr (VI)) is extremely toxic and exhibits carcinogenic effects on biological systems due to strong oxidizing nature. In aqueous waste $\mathrm{Cr}$ (VI) is present as either dichromate anion $\left(\mathrm{Cr}_{2} \mathrm{O}_{7}^{-2}\right)$ in acidic environments or as chromate anion $\left(\mathrm{CrO}_{4}^{-2}\right)$ in alkaline environments. The conventional process used for removal of $\mathrm{Cr}$ (VI) from wastewater is reduction and its precipitation as chromium (III) hydroxide. This procedure is not completely satisfactory and has several disadvantages like generation of a large amount of secondary waste products due to various reagents used in a series of treatments such as reduction of $\mathrm{Cr}$ (VI), neutralization of acid solution and precipitation. There is a need for the development of low cost, easily available materials that could allow $\mathrm{Cr}$ (VI) removing and recovering, economically. In recent times, a great deal of interest has been given to the utilization of agriculture by-products biodegradable products as adsorbents for the removal of toxic and valuable heavy metals from industrial and municipal wastewater effluents. These materials are high availability, no need for complicated regeneration process, low cost materials. As well as, they are capable of binding to heavy metals by adsorption, chelating and ion exchange [1]-[3].

As low-cost, renewable, biodegradable polymers, starch-based products have been proposed as chelating agents

Manuscript received April 14, 2013; revised July 2, 2013.

The authors are with School of Environmental Engineering, Institute of Engineering, Suranaree University of Technology, Nakhon Ratchasima, Thailand 30000 (e-mail: patcha@sut.ac.th). to remove heavy metal ions from electroplate metallurgy wastewater. $\mathrm{Xu}$ et al. (2004) [4] studied the adsorption process of $\mathrm{Pb}$ (II) by crosslinked amphoteric starch with quaternary ammonium and carboxymethyl groups. Khalil and Abdel-Halim (2000) [5] prepared anionic starches containing carboxyl groups and used them as chelating agents for removal of some divalent metal ions. Kweon and Choi [6] investigated the adsorption of divalent metal ions by succinylated and oxidized corn starches. Zhang and Chen (2002) [7] investigated crosslinked starch graft copolymers containing amine groups as the adsorbents for $\mathrm{Pb}$ (II) and $\mathrm{Cu}$ (II). Kim and Lim (1999) [8] reported the removal of heavy metal ions from water by crosslinked carboxymethyl corn starch. Amino Starch is also developed for heavy metal removal. Xiang and Li (2004) [9] found amino starch has high adsorption capacity for $\mathrm{Cu}$ (II). However, the chromium-binding properties of starch-based materials are not well studied. Thus, this study, amino modified tapioca starch adsorption capabilities were tested for Cr (VI) metal ion at several $\mathrm{pHs}$, reaction times and varying metal ion concentrations. Once the optimum conditions were determined, the adsorption capacities of the unmodified tapioca starch were obtained.

\section{MATERIAL AND METHODS}

\section{A. Absorbents}

Two types of modified tapioca starch that used as the absorbents were amino modified tapioca starch (AMTS). Also, unmodified tapioca starch were evaluated the adsorption capacities, too.

\section{B. Sorption Experiments}

Sorption studies were performed by the batch technique for evaluated the influencing of $\mathrm{pH}, \mathrm{Cr}$ (VI) concentration, equilibrium isotherm and adsorption kinetics [4], [5]. The effect of $\mathrm{pH}$ was observed by studying the adsorption of hexavalent chromium over a $\mathrm{pH}$ range of $2-10$. For these experiments, a series of $250 \mathrm{~mL}$ conical flasks were employed. Each flask was filled with $50 \mathrm{~mL}$ of $\mathrm{Cr}$ (VI) solution having a concentration of $30 \mathrm{mg} / \mathrm{L}$ at varying $\mathrm{pH}$. For influencing of $\mathrm{Cr}(\mathrm{VI})$ concentration, equilibrium sorption studies and adsorption kinetics, a fixed mass of starch was weighed about $0.1000 \mathrm{~g}$ into flasks and contacted with $50 \mathrm{~mL}$ of hexavalent solutions with predetermined initial concentrations (varied from $10 \mathrm{mg} / \mathrm{L}$ to $50 \mathrm{mg} / \mathrm{L}$ ). The $\mathrm{pH}$ of the solutions was adjusted to 4.0. Then the flasks were sealed and agitated for $24 \mathrm{~h}$ at $200 \mathrm{rpm}$ in the thermostatic shaker bath. The temperature was maintained at $25 \pm 1^{\circ} \mathrm{C}$. After filtration, the concentrations of chromium solutions were determined. 


\section{Ultrafiltration Experiment}

This study was evaluated via the amino starch crosslinking and Ultrafiltration (UF) continuous experimental runs during 3 mounts of operating periods. This study were integrated the starch separation efficiency and the optimum operating condition for UF unit. The UF experimental module consists of a feed tank, ultrafiltration membrane, wash out and permeate tanks. UF membrane is a cross-flow type as shown in Fig. 1. The permeate water and air were used for recirculation for backwashing. The characteristics of membrane and operating condition of UF unit were shown in Table I and Table II, respectively. This experiment sets up for evaluated the effect of the initial permeate flux, effect of the retentate pressure molar ratio of chromate to modified starch and organic effluents.

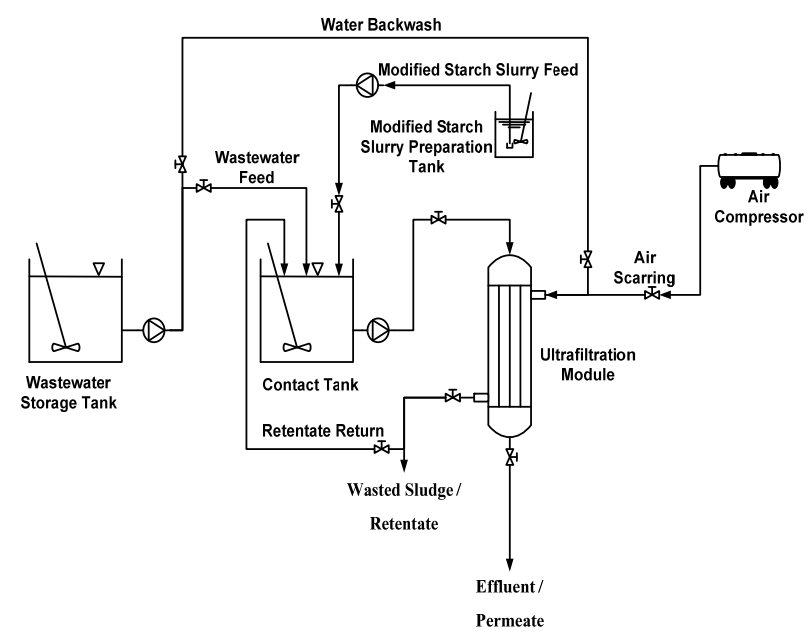

Fig. 1. Ultrafiltration experimental set up.

TABLE I: CHARACTERISTICS OF ULTRAFILTRATION MEMBRANES

\begin{tabular}{|l|l|}
\hline Manufacturer: Ultra-Flo $^{\circledR}$ & Surface Area: $50 \mathrm{ft}^{2}$ \\
\hline Model: BT-420 & pH range (operating): 3-9 \\
\hline Configuration: Hollow Fiber ( Out-to-In ) & $\begin{array}{l}\text { Fiber Material: } \\
\text { Hydrophilic PAN }\end{array}$ \\
\hline
\end{tabular}

TABLE II: EXPERIMENTAL CONDITIONS

\begin{tabular}{|l|l|}
\hline Parameters & Conditions \\
\hline Retentate pressure, $\mathrm{MPa}$ & $0.14,0.18,0.20$ \\
\hline $\mathrm{pH}$ & 5.0 \\
\hline Initial concentration of chromate, $\mathrm{mg} / \mathrm{L}$ & $20,29,50,116$ \\
\hline $\mathrm{MWCO}, \mathrm{Da}$ & 100,000 \\
\hline Molar ratio of chromate to modified starch & $1: 2,1: 5,1: 10$ \\
\hline Initial permeate flux, $\mathrm{L} / \mathrm{m}^{2} . \mathrm{h}$ & $30,40,50$ \\
\hline
\end{tabular}

\section{Analytical Methods}

After achieving the batch conditions, the $\mathrm{Cr}$ (VI) concentration in the influent and effluent samples were analyzed three duplicates following the test methods for evaluation solid waste physical/chemical methods (SW-846) [10].

\section{RESUlTS AND DisCUSSION}

\section{A. Influencing of $p H$}

The adsorption behaviors and influence of $\mathrm{pH}$ are studies in order to understand the mechanism that governs hexavalent chromium removal. The $\mathrm{pH}$ of the aqueous solutions is an important controlling parameter in the heavy metal adsorption processes. Two cross linked of tapioca starch were achieved in acidic condition at $\mathrm{pH} 5$ of amino and carboxyl as shown in Fig. 2. The increased of $\mathrm{pH}$ values, the capacity were decreases. These facts suggest that the interaction of modified starch with hexavalent chromium is based on electrostatic attraction. It has been well understood that about $82 \%$ total $\mathrm{Cr}(\mathrm{VI})$ is as $\mathrm{HCrO}_{4}{ }^{-}$and the rest as $\mathrm{Cr}_{2} \mathrm{O}_{7}{ }^{2-}$ at $\mathrm{pH}$ values from 0 to 5. Therefore $\mathrm{HCrO}_{4}{ }^{-}$plays an important role interacting with modified tapioca starch. Also in the presence of $\mathrm{H}^{+}$, the amino groups of modified tapioca starch become protonated. Then the adsorption process is predominately due to $-\mathrm{NH}_{3}{ }^{+} \mathrm{HCrO}_{4}^{-}$and $=\mathrm{NH}_{2}{ }^{+} \cdot \mathrm{HCrO}_{4}{ }^{-}$ ionic interactions.

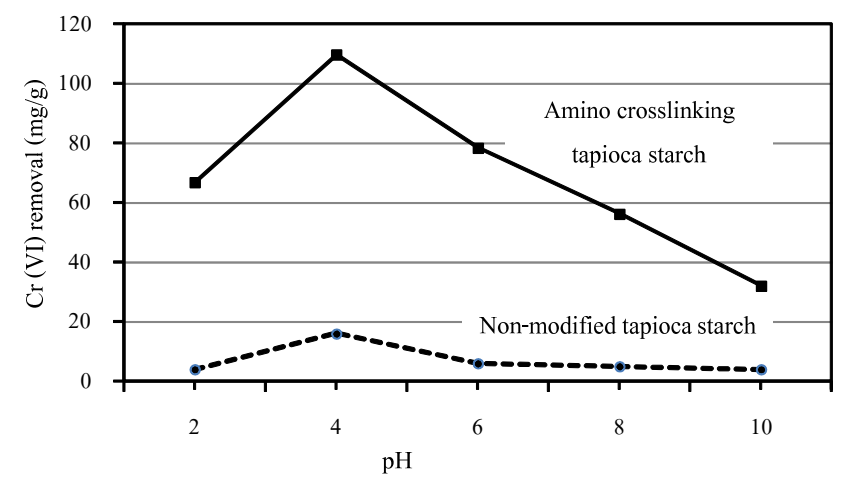

Fig. 2. Influencing of $\mathrm{pH}$ on the adsorption of hexavalent chromium by AMTS and unmodified tapioca starch.

\section{B. Influencing of Contact Times}

The plot represents the amounts of chromium adsorbed onto modified starch versus time, for an initial chromium concentration of $30 \mathrm{mg} / \mathrm{L}$ are shown in Fig. 3. The rates of uptake of chromium are rapid in the beginning and $50 \%$ of the ultimate adsorption occurs within the first hour of contact. The equilibrium achieves after $5 \mathrm{~h}$. To evaluate the adsorption process, the pseudo-second-order model was applied in this study. It can be seen that the kinetic model gives goodness of fits. The chromium adsorptions onto two cross-linked starch were shown the similar behaviors. Various types of adsorption isotherms (Langmuir and Freundlich) were tested to fit the experimental data. The overall results can be concluded that modified starch might have ramifications for applications of amino-starch for controlled delivery of hexavalent chromium in aqueous solution.

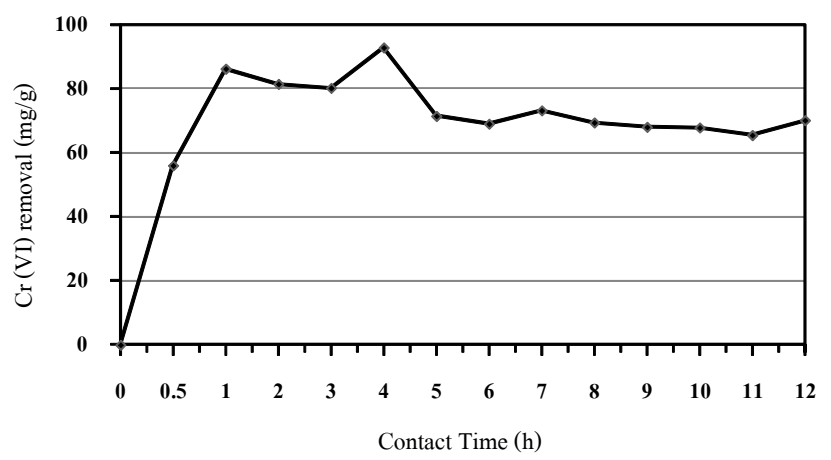

Fig. 3. Influencing of contact time on the adsorption of hexavalent chromium by AMTS. 

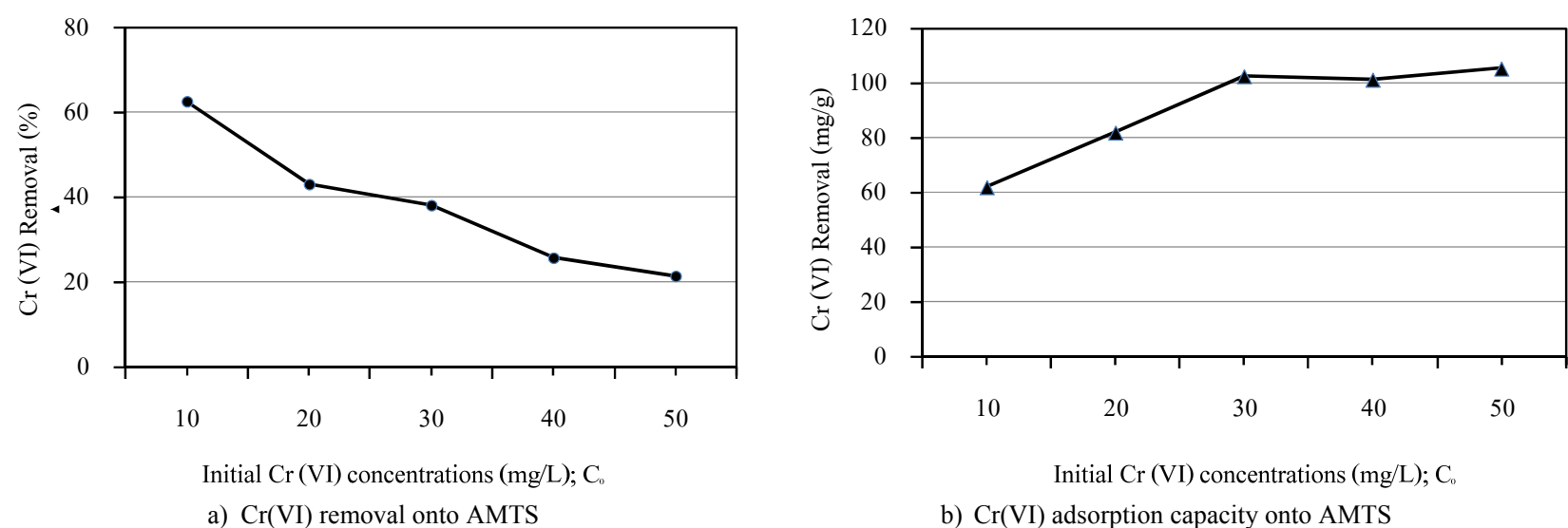

o AMTS

b) $\mathrm{Cr}(\mathrm{VI})$ adsorption capacity onto AMTS

Fig. 4. Effect of initial chromium (VI) concentration on adsorption onto amino modified tapioca starch (AMTS).

\section{Effect of Cr (VI) Concentrations on Absorption Capacity}

The effect of initial Cr (VI) concentration on adsorption was studied at the optimized $\mathrm{pH}$ 4.0. It can be seen that $\mathrm{Cr}$ (VI) adsorption onto modified starch was dependent on the initial concentration of $\mathrm{Cr}$ (VI) in solution as shown in Fig. 4. The removal percentage decreases from $85 \%$ to $50 \%$ with increasing initial concentration of $\mathrm{Cr}(\mathrm{VI})$ from $10 \mathrm{mg} / \mathrm{L}$ to 50 $\mathrm{mg} / \mathrm{L}$. The kinetics of hexavalent chromium adsorption onto modified starch was obtained by batch contact time study.

\section{Adsorption Kinetics Study}

\section{1) Pseudo first order equation}

The adsorption rate can be described by the first-order kinetic model, and which expressed [11], [12]:

$$
-\ln \left(1-\frac{Q_{t}}{Q_{e}}\right)=k_{1} t
$$

where: $k_{1}$ is the first-order equilibrium constant, and where $Q_{t}$ and $Q_{\mathrm{e}}$ (all in $\mathrm{mg} / \mathrm{g}$ ) represent adsorption value of $\mathrm{Cr}(\mathrm{VI})$ ions in aqueous solutions at any time $\mathrm{t}$ and at equilibrium, respectively. The values of $-\ln \left(1-Q_{t} / Q_{e}\right)$ were linearly correlated with $t$ are shown on Fig. 4a. From this figure, the value of $k_{1}$ was determined from the slope of the plots. Adsorption rate constants $\mathrm{k}_{1}$ and $R^{2}$ for AMTS were 0.2901 $\mathrm{min}^{-1}$ and 0.8688 , respectively. The $k_{1}$ values are generally higher for $\mathrm{Cr}(\mathrm{VI})$ confirming our initial proposed trend for the sorption process.

\section{2) Pseudo second order equation}

The pseudo second order adsorption kinetic rate equation as expressed by Dong et al. (2010) [11] and Cheng et al. (2009) [12] is:

$$
\frac{d Q_{t}}{d Q}=k_{2}\left(Q-Q_{t}\right)^{2}
$$

where: $k_{2}$ is the rate constant of pseudo second order adsorption $\left(\mathrm{mg}^{-1} \mathrm{~min}^{-1}\right)$ From the boundary conditions $t=0$ to $t=t$ and $Q_{t}=0$ to $Q_{t}=Q_{t}$, the integrated form of Equation (2) becomes:

$$
\frac{1}{\left(Q-Q_{t}\right)}=\frac{1}{\left(Q-k_{t}\right)}
$$

This is the integrated rate law for a pseudo second order reaction. Equation (3) can be rearranged to obtain Equation (4), which has a linear form:

$$
\frac{t}{Q_{t}}=\frac{1}{k_{2} Q_{e}^{2}}+\frac{1}{Q_{e}} t
$$

If the initial adsorption rate, $\mathrm{h}_{\mathrm{o}}\left(\mathrm{mg} \cdot \mathrm{g}^{-1} \mathrm{~min}^{-1}\right)$ is:

$$
h_{0}=k_{2} Q_{e}^{2}
$$

Then Equations (4) and (5) becomes:

$$
\frac{t}{Q_{t}}=\frac{1}{h_{0}}+\frac{1}{Q_{e}} t
$$

Thus, from Equation (6) plots of $\left(t / Q_{t}\right)$ and $t$ were made and the values of $Q_{e}$ and $k_{2}$ determined from the slopes and intercepts respectively. The predictive linear regression equations and $R^{2}$ values for the pseudo second order equation is given on Table III also of the values of $Q_{\mathrm{e}}, h_{0}$ and $k_{2}$ too. The values of $R^{2}$ show that the pseudo second order equation gave a better fit to the sorption process than a pseudo first order model. The least value of $\mathrm{R}^{2}$ is 0.9775 .

TABLE III: PARAMETERS OF PESUEdo SECOND ORder Kinetic MOdel OF CR (VI) ADSORPTION ONTO AMTS

\begin{tabular}{|l|l|}
\hline \multicolumn{1}{|c|}{ Parameters } & Values \\
\hline$k_{2}(\mathrm{~g} / \mathrm{mg}-\mathrm{min})$ & 0.3252 \\
\hline Initial sorption rate, $\mathrm{h}_{0}(\mathrm{mg} / \mathrm{g}-\mathrm{min})$ & 1.3691 \\
\hline Calculated, $Q_{e}(\mathrm{mg} / \mathrm{g})$ & 2.0517 \\
\hline Correlation coefficients, $R^{2}$ & 0.9775 \\
\hline
\end{tabular}

\section{E. Equilibrium Isotherms}

Adsorption isotherms describe how adsorbates interact with adsorbents. It is of importance in optimizing the use of adsorbents. Equilibrium data were obtained by using batch technology described in experimental section at the optimum $\mathrm{pH}$ 4.0. Various types of adsorption isotherms (Langmuir and Freundlich) were tested to fit the experimental data. The well-known Langmuir isotherm originally proposed to describe the adsorption of gas molecules onto metal surfaces [12]. The model assumes uniform energies of adsorption onto the surface and no migration of adsorbate in the plane of surface. Moreover the Langmuir adsorption isotherm has successfully applied to many other real sorption courses of monolayer sorption, and its linear form is written as

$$
\frac{C_{e}}{Q_{e}}=\frac{1}{a . b}+\frac{1}{a} C_{e}
$$


where $Q_{e}$ is the adsorbed amount of the adsorbate at equilibrium, $C_{e}$ is the adsorbate concentration at equilibrium in aqueous solution. The Langmuir isotherm parameters are a and $b$. The capacity of the sorbent can be evaluated by a, and the parameter $b$ includes various physical constants [12].

The values of $Q_{0}$ and $\mathrm{b}$ are listed in Table IV. The results indicate that the adsorbent has largest adsorption capacity in the case of $\mathrm{Cr}$ (VI). So we got a conclusion that the adsorption of $\mathrm{Cr}$ (VI) on amino tapioca starch was monolayer adsorption which belonged to chemisorptions.

TABLE IV: PARAMETERS OF LINEARZED LANGMUIR AND FREUDLICH ISOTHERMS OF HEXAVALENT CHROMIUM ADSORPTION ONTO AMTS

\begin{tabular}{|c|c|c|c|c|c|}
\hline \multicolumn{3}{|c|}{ Langmuir isotherm } & \multicolumn{3}{c|}{ Freundlich isotherm } \\
\hline $\mathrm{a}(\mathrm{mg} / \mathrm{L})$ & $\begin{array}{c}\mathrm{b} \\
(\mathrm{L} / \mathrm{mg})\end{array}$ & $\mathrm{R}^{2}$ & $\begin{array}{c}\mathrm{K}_{\mathrm{f}} \\
(\mathrm{mg} / \mathrm{g}) *(\mathrm{~L} / \mathrm{g})\end{array}$ & $\mathrm{n}$ & $\mathrm{R}^{2}$ \\
\hline 27.7008 & 0.2298 & 0.9406 & 5.2028 & 4.9309 & 0.9284 \\
\hline
\end{tabular}

Another isotherm is Freundlich equation describing heterogeneous systems [12]. It is an empirical equation, and the linear form is as follows

$$
\ln Q_{e}=\ln K_{f}+\frac{1}{n} \ln C_{e}
$$

where $K_{f}$ is the Freundlich constant, and $1 / n$ is the heterogeneity factor. Parameters of linear form of Langmuir isotherm (Eq. 7) and Freundlich isotherm (Eq. 8) are showed in Table II. The results suggest that the equilibrium data were well described by Freundlich isotherm, probably due to the real heterogeneous nature of the surface sites like $-\mathrm{NH}_{3}{ }^{+}$and $=\mathrm{NH}_{2}{ }^{+}$involved in the chromium uptake. To a less extent, the Langmuir isotherm also gives acceptable fit indicating the hexavalent ions absorbed form monolayer coverage on the adsorbent surface. Generally the application of the Langmuir model seemed to be more appropriate than that of Freundlich model. This interesting chromium (VI) adsorption behavior was also found on polyaniline that contained abundant amine groups [11], [12].

\section{F. Effect of the Initial Permeate Flux}

This study was evaluated via the amino starch crosslinking and UF continuous experimental runs during 3 mounts of operating periods. The average chromate removal efficiency was $94 \%$ at the initial permeate flux of $50 \mathrm{~L} / \mathrm{m}^{2} . \mathrm{h}$, while it was $84 \%$ and $72 \%$ for the initial operating permeate fluxes of $40 \mathrm{~L} / \mathrm{m}^{2} . \mathrm{h}$ and $30 \mathrm{~L} / \mathrm{m}^{2} . \mathrm{h}$ respectively. The molar ratio of chromate to modified starch concentration was increased with the increase of the operating initial permeate flux enhancing higher chromate removal from the feed solution. This result is analogous to the previous one. Due to the applied pressure, the pollutants adsorbed in the pore of the membrane move slowly to permeate water during filtration. Thus, the permeate chromate concentration increased with the passage of time. Relative flux is an important parameter in filtration. The average relative fluxes were $0.85,0.65$ and 0.55 respectively for the initial permeate fluxes of about 30 $\mathrm{L} / \mathrm{m}^{2} . \mathrm{h}, 40 \mathrm{~L} / \mathrm{m}^{2} . \mathrm{h}$ and $50 \mathrm{~L} / \mathrm{m}^{2} . h$ respectively. With the increase of the operating initial permeate flux there was a sharp reductionin the relative flux. Similar results were presented by previous researchers [13]. Concentration polarization hinders the permeate flux which can be minimized by selecting an optimum initial permeate flux. Considering higher chromate removal efficiency and higher permeate flux, the initial permeate flux of $43.7 \mathrm{~L} / \mathrm{m}^{2} . \mathrm{h}(40$ $\mathrm{mL} / \mathrm{min}$ ) was the optimum permeate flux in the experimental condition.

\section{G. Effect of the Retentate Pressure}

The average chromate removal efficiency was $94 \%$ at the initial retentate pressure of $0.2 \mathrm{MPa}$, it was $84 \%$ and $72 \%$ respectively at the pressures of $0.18 \mathrm{MPa}$ and $0.14 \mathrm{MPa}$. A similar result was presented on chromate removal in a lower MWCO membrane (10 KD) in the previous study [13]. It was reported that in UF the rejected modified starch are accumulated near the membrane surface increasing its concentration higher than in the bulk solution [14], [15]. It eventually enhances the metal ions removal.

As results shown, the specific flux decreased with the increase of the operating initial retentate pressure. Increased concentration polarization at a higher initial applied retentate pressure caused a faster reduction in the permeate flux. Therefore a lower operating retentate pressure should be chosen to get a higher specific flux.

\section{H. Molar Ratio of Chromate to Modified Starch}

Another series of experiments was conducted at various molar ratios of chromate to modified starch. The chromate removal was $94.5 \%$ for the molar ratio of $1: 10$. The removal decreased to $90.8 \%$ and $73.9 \%$ at the molar ratios of $1: 5$ and 1:2 respectively. The corresponding permeates chromate concentrations were $0.18 \mathrm{mg} / \mathrm{L}, 0.52 \mathrm{mg} / \mathrm{L}$ and $4.32 \mathrm{mg} / \mathrm{L}$ respectively. Chromate removal was higher for higher initial molar ratios of chromate to modified starch concentration, which produces more absorbent. It results in a larger surface area of modified starch available for electrostatic attraction of chromate ions. While filtering through the UF membrane, modified starches were retained on the membrane surface along with which chromate ions were also retained.

During filtration in addition to concentration polarization, adsorption of molar ratios of chromate to modified starch takes place on the membrane surface and in its pores. The decline in the permeate flux with the increase of the molar ratio of chromate to modified starch is increase. The permeate fluxes were $32.3 \mathrm{~L} / \mathrm{m}^{2} . \mathrm{h}, 29.4 \mathrm{~L} / \mathrm{m}^{2} . \mathrm{h}$ and 22.6 $\mathrm{L} / \mathrm{m}^{2}$.h respectively for the molar ratios of chromate to molar ratios of chromate to modified starch of 1:2, 1:5 and 1:10 respectively. At a higher molar ratios of chromate to modified starch concentration, more modified starch were accumulated on the membrane surface reducing the driving force and consequently lowering the permeate flux. Considering a higher chromate removal efficiency and a higher permeate flux, the molar ratio of 1:5 was found to be the most appropriate molar ratio.

\section{Organic Effluents}

This study was evaluated the chemical oxygen demands (COD) contents of the permeate water in variances operating condition. The overall results showed that the COD effluents were less than $20 \mathrm{mg} / \mathrm{L}$. These were sufficiently to the industrial effluent standards.

\section{CONCLUSIONS}

The adsorption activity of modified tapioca starch for $\mathrm{Cr}$ (VI) was studied in terms of adsorption capacities, 
influencing of $\mathrm{pH}$, contact time, and $\mathrm{Cr}$ (VI) concentrations, and adsorbent reuse was also studied. The modified tapioca starch was very effective for the adsorption of $\mathrm{Cr}$ (VI), and stability. Two cross linked of tapioca starch were achieved in acidic condition at pH 5 of amino and carboxyl crosslinkes. The increased of $\mathrm{pH}$ values, the capacity were decreases. The rates of uptake of chromium are rapid in the beginning and 50\% of the ultimate adsorption occurs within the first hour of contact. The equilibrium achieves after $5 \mathrm{~h}$. The effect of initial $\mathrm{Cr}$ (VI) concentration on adsorption was studied at the optimized $\mathrm{pH} 4.0$. The removal percentage decreases from $85 \%$ to $50 \%$ with increasing initial concentration of $\mathrm{Cr}$ (VI) from $10 \mathrm{mg} / \mathrm{L}$ to $50 \mathrm{mg} / \mathrm{L}$. During the UF experiments, higher chromate removal efficiency and higher permeate flux, the initial permeate flux of $43.7 \mathrm{~L} / \mathrm{m}^{2} . \mathrm{h}(40 \mathrm{~mL} / \mathrm{min})$ was the optimum permeate flux in the experimental condition. The specific flux decreased with the increase of the operating initial retentate pressure. Increased concentration polarization at a higher initial applied retentate pressure caused a faster reduction in the permeate flux. The molar ratio of 1:5 was found to be the most appropriate molar ratio. Also, modified starch cannot contaminated in the UF permeate water.

\section{REFERENCES}

[1] R. Klimaviciute, J. Bendoraitiene, R. Rutkaite, and A. Zemaitaitis, "Adsorption of hexavalent chromium on cationic cross-linked starches of different botanic origins," Journal of Hazardous Materials, vol. 181, pp. 624-632, 2010.

[2] A. A. Abia, M. H. Jr, and O. Didi, "The use of chemically modified and unmodified cassava waste for removal of $\mathrm{Cd}, \mathrm{Cu}$ and $\mathrm{Zn}$ ions from aqueous solution," Bioresource Technology, vol. 90, pp. 345-348, 2003.

[3] M. Nichifor, M. C. Stanciu, and B. Simionescu, "New cationic hydrophilic and amphillic polysaccharides synthesized by one pot procedure," Carbohydrate Polymer, vol. 82, pp. 965-975, 2010.

[4] S. M. Xu, S. Feng, G. Peng, and J. D. Wang, "Adsorption of Zn (II) ion onto crosslinked amphoteric starch in aqueous solutions," J. Polym. Res, vol. 11, pp. 105-108, 2004.
[5] M. I. Khalil and M. G. Abdel-Halim, "Preparation of some starch-based neutral chelating agents," Carbohydr. Res, vol. 324, pp. 189-199, 2000.

[6] D. K. Kweon and J. K. Choi, "Adsorption of divalent metal ions by succinylated and oxidized corn starches," Carbohydr. Polym., vol. 46, pp. 171-177, 2001.

[7] L. M. Zhang and D. Q. Chen, "An investigation of adsorption of lead (II) and copper (II) ions by water-insoluble starch graft copolymers," Colloids Surf., vol. 205, pp. 231-236, 2002.

[8] B. S. Kim and S. T. Lim, "Removal of heavy metal ions from water by cross-linked carboxymethyl corn starch," Carbohydr. Polym., vol. 39, pp. 217-223, 1999

[9] B. Xiang and Y. J. Li, "Removal of Cu (II) from aqueous solutions by chelating starch derivatives," J. Appl. Polym. Sci., vol. 92, pp. 3881-3885, 2004

[10]US. EPA. (2011). The test methods for evaluation solid waste physical/chemical methods (SW-846) [online]. Available: http://www.epa.gov/osw/hazard/testmethods/sw846/online/7_series.ht $\mathrm{m}$

[11]A. Dong, J. Xie, W. Wang, L. Yu, Q. Lui, and Y. Yin, “A novel method for amino starch preparation and its adsorption for Cu (II) and $\mathrm{Cr}$ (VI)," Journal of Hazardous Materials, vol. 181, pp. 448-454, 2010.

[12] R. Cheng, S. Ou, B. Xiang, Y. Li, and Q. Liao, “Adsorption behavior of hexavalent chromium on synthesized ethylenediamine modified starch" Journal of Polymer Research, vol. 16. pp. 703-708, 2009.

[13]H. K. Shon, S. Vigneswaran, I. S. Kim, J. Cho, and H. H. Ngo, "Effect of pretreatment on the fouling of membranes: application in biologically treated sewage effluent," J. Membr. Sci., vol. 234, pp. 111, 2004.

[14]L. Gzara and M. Dhahbi, "Removal of chromate by micellar-enhanced ultrafiltration using cationic surfactants," Desalination, vol. 137, pp. 241, 2001.

[15]C. Brasquet, E. Subrenat, and P. Le Cloirec, "Removal of phenolic compounds from aqueous solution by activated carbon clothes," Wat Sci. Tech., vol. 39, issue 10-11, pp. 201, 1999.

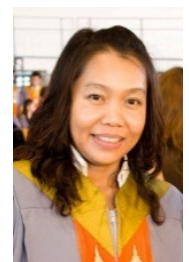

Patcharin Racho is a Ph.D. in Environmental Engineering, she took a position as a lecturer in Engineering Institute of Suranaree University of Technology, Nakhon Ratchasima, Thailand. Her research interests are in biological wastewater treatment, chemisoprtion, and functional material that developed for heavy metal removal is the most of her researches. 